\title{
BMJ Open Individualised physical exercise training and enhanced protein intake in older citizens during municipality- based rehabilitation: protocol for a randomised controlled trial
}

Sanel Teljigovic (i) , ${ }^{1,2}$ Karen Søgaard (D) , ${ }^{2}$ Louise Fleng Sandal (i) , ${ }^{2}$ Tina Dalager, ${ }^{2}$ Nina Odgaard Nielsen, ${ }^{1}$ Gisela Sjøgaard, ${ }^{2}$ Lars Holm ${ }^{3}$

To cite: Teljigovic S, Søgaard K, Sandal LF, et al. Individualised physical exercise training and enhanced protein intake in older citizens during municipalitybased rehabilitation: protocol for a randomised controlled trial. BMJ Open 2020;10:e041605. doi:10.1136/ bmjopen-2020-041605

- Prepublication history for this paper is available online. To view these files, please visit the journal online (http://dx.doi. org/10.1136/bmjopen-2020041605).

Received 12 June 2020 Revised 21 0ctober 2020 Accepted 28 0ctober 2020

Check for updates

(c) Author(s) (or their employer(s)) 2020. Re-use permitted under CC BY-NC. No commercial re-use. See rights and permissions. Published by BMJ.

${ }^{1}$ Department of Physiotherapy, University College Absalon,

Naestved, Denmark

${ }^{2}$ Department of Sports Science and Clinical Biomechanics, University of Southern Denmark, Odense, Denmark

${ }^{3}$ School of Sport, Exercise and Rehabilitation Sciences, University of Birmingham, Birmingham, UK

Correspondence to

Sanel Teljigovic; sate@pha.dk

\section{ABSTRACT}

Introduction Successful rehabilitation of the growing number of older citizens receiving healthcare services can lead to preservation of functional independence and improvement in quality of life. Adequate intake of dietary protein and physical training are key factors in counteracting the age-related decline in strength performance and physical function. However, during rehabilitation, many older people/persons have insufficient protein intake, and difficulties in performing exercise training with sufficient intensity and volume. The primary aim of this trial is to investigate if individualised physical exercise training programmes combined with increased protein intake (IPET+P) can improve measures on all International Classification of Functioning, Disability and Health levels, such as strength, gait speed and healthrelated quality of life, when compared with care as usual in municipality-based rehabilitation alone (usual care, UC) or care as usual in combination with increased protein intake $(\mathrm{UC}+\mathrm{P})$. Further, the trial investigates whether $\mathrm{UC}+\mathrm{P}$ will potentiate more significant improvements in outcome measures than UC.

Methods and analysis The trial is a three-armed multicentre, block-randomised controlled trial consisting of a 12-week intervention period with a 1-year follow-up. Citizens above 65 years referred to rehabilitation in the municipality without restricting comorbidities are eligible. Participants are randomised to either a UC group, a UC group with protein supplementation receiving $27.5 \mathrm{~g}$ protein/day $(\mathrm{UC}+\mathrm{P})$, or an IPET+P supplementation of $27.5 \mathrm{~g}$ protein/day. The Short Musculoskeletal Function Assessment questionnaire is the primary outcome. Ethics and dissemination Approvals from The Ethics Committee in Region Zealand, Denmark (SJ-758), and the General Data Protection Regulation at the University of Southern Denmark, Odense (10.330) have been obtained. Trial registration number NCT04091308

\section{INTRODUCTION}

The older population is growing fast in Westernised societies. ${ }^{1}$ Data from EUROSTAT indicates that the number of older adults $>65$
Strengths and limitations of this study

- The trial is conducted as a multicentre randomised controlled trial with a 1-year follow-up investigating outcomes of rehabilitation in an older population on all variables of the 'International Classification of Functioning, Disability and Health'

- High compliance regarding protein supplementation will potentially result from offering low-volume, high quantity protein-enriched yoghurts with different flavours.

- This trial is conducted in a real-life clinical setting involving health professionals and the relevant target population to increase external validity.

- Real-life clinical setting may affect compliance as readmissions to hospital and other practical challenges can not be controlled.

- The trial investigates only the effect of individualising physical exercise training in addition to protein intake as individualised physical exercise training alone was not included due to limited resources.

years in the European Union will increase by $10.2 \%$ in total until $2080 .^{2}$ In Denmark, the annual growth in number of citizens $>65$ years will increase by approximately $2 \%$ and for citizens $>80$ years by 3\% until 2025 . According to Danish Regions, additionally 120000 citizens aged $>65$ will be in contact with the Danish healthcare system towards 2025. ${ }^{3}$ Consequently, more older citizens will receive municipality-based rehabilitation. With the increasing number of older citizens, it is becoming even more important to find ways to use the potential of each older individual, thereby empowering them to independent living. ${ }^{4}$

Poor health in combination with ageing results in declines on all International Classification of Functioning, Disability and Health (ICF) parameters such as body composition, 
strength, physical functioning and mental well-being, which puts the individuals at risk for multimorbidity conditions. ${ }^{56}$ During the last century, chronic health problems have taken a role as a dominant healthcare burden, and almost all chronic conditions are strongly related to ageing, which in turn is related to declines in physical functioning. ${ }^{6}$ However, the accelerated worsening in body composition and muscular strength can be partly counteracted through different strategies in healthy as well as clinical populations. ${ }^{78}$ Two modifiable key factors: higher intake of dietary protein and performing physical exercise training may counteract such declines. ${ }^{9}$ These two factors can potentiate each other, and when pursued by older citizens, they can decrease the extent of secondary health problems and costs of health services, thus beneficial for both the older individual and the society. ${ }^{10}$

\section{Physical exercise training}

Danish national clinical guidelines recently highlighted challenges regarding the specific and strong recommendations for nutrition and exercise to improve function in older citizens, due to the low level of evidence supporting the recommendations. ${ }^{10}$ Nevertheless, the literature agrees that physical exercise training should be prescribed for healthy individuals as well as those with specific disorder. ${ }^{112}$ However, many older citizens find it difficult to engage in regular physical exercise, mainly if discomfort and pain are present during exercise.${ }^{13}$ Kruger et al showed that only $\sim 10 \%-12 \%$ of the older aged $>65$ years participate in regular resistance training. ${ }^{14} 15$

It is common practice when referred to municipalitybased rehabilitation in Denmark that the referring part (hospital, visitation, personal physician) provides a rehabilitation plan. This plan is used to focus the rehabilitation, however, rehabilitation is solely focused on interventions that typically address one disorder without taking overall health into account. A possible new approach to overcome low compliance could be to prescribe individualised exercise programmes, that take musculoskeletal disorders as well as general health into account. In randomised controlled trials, it is common to administer the same treatment to all participants in the intervention group. An alternative could be developed to promote health through individualised exercise, which may maximise the individual's outcome of regular exercise and rehabilitation. Sjøgaard et al designed a conceptual model for planning the optimal individually tailored physical exercise training (IPET concept) ${ }^{16}$ This was based on individual health check, physical capacity, existing guidelines and current recommendations in categories of muscle strength, cardiorespiratory fitness and functional training and balance training for the working-age population. ${ }^{16}$ Even though the conceptual model has been tested on middle-aged adults, it may be considered a potential model for individualising exercise for older citizens. Another aspect is that decreased mobility may discourage the olders from participating in supervised group-based physical activity at health centres. ${ }^{17}$ Consequently, physical exercise should, therefore, be easily accessed and preferentially an integrated part of daily living.

\section{Supervision of home-based training}

A challenge with self-administered training is to know if the exercise is performed correctly. In a recent study by Faber $e t a l$, the majority of the participants advised to home-based exercises did not perform the exercises as administered in regard to time under tension, 2 weeks after the initial instruction. ${ }^{18}$ A relatively new technology (Sports sensor, University of Southern Denmark) to monitor and quantify home-based exercise has been developed, consisting of a built-in sensor attached externally to an elastic exercise band (TheraBand). ${ }^{19}$

\section{Protein intake}

Beneficial effects of higher protein intake might be necessary to overcome a decreased response to nutrients for muscle protein anabolism. ${ }^{20}$ However, a significant number of older citizens do not meet the recommended dietary protein intake. Further, when conducting exercise, the myofibrillar protein synthesis is enhanced by assuring sufficient amounts of essential amino acids, hence, a protein supplement may be clinically meaningful in order to support an exercise response.

This randomised controlled trial aims to investigate if IPET programmes combined with increased protein intake $(\mathrm{IPET}+\mathrm{P})$ can improve measures on all three ICF levels when compared with care as usual in municipalitybased rehabilitation (usual care, UC) alone or care as usual in combination with increased protein intake $(\mathrm{UC}+\mathrm{P})$. Further, the trial investigates whether $\mathrm{UC}+\mathrm{P}$ will potentiate more significant improvements in outcome measures than UC. The Short Musculoskeletal Function Assessment-Dysfunction Index (SMFA-D) is chosen as a suitable primary outcome to reflect the self-reported function for participants with various disorders. ${ }^{21}$ The primary hypotheses tested are that (1) SMFA-D improvements are larger in UC+P compared with UC (2) and larger in IPET $+\mathrm{P}$ compared with $\mathrm{UC}+\mathrm{P}$ and $\mathrm{UC}$.

\section{METHODS: PARTICIPANTS, INTERVENTIONS AND OUTCOMES}

This protocol is written on the basis of Standard Protocol Items: Recommendations for Interventional Trials guidance for reporting protocols for clinical trials. ${ }^{22}$

\section{Trial design}

The trial is a multicentre, block-randomised controlled trial with three parallel arms and a 12-week intervention period with a 1-year follow-up.

A total of 177 participants will be consecutively included from municipality rehabilitation centres in Slagelse and Korsør, Denmark, and after baseline testing randomised to one of three groups: $\mathrm{UC}, \mathrm{UC}+\mathrm{P}$ or IPET $+\mathrm{P}$.

The trial expects to enrol participants to baseline testing between January 2020 and November 2021, with the 1-year follow-up in November 2022. 


\section{Box 1 Exclusion criteria}

Inability to speak or read Danish

- Renal diseases

- Active cancer

- Upper or lower limb amputations

- Milk/lactose allergy or intolerance

- Blood pressure $>180 / 90$

- Pacemaker/other implanted electrical stimulants

- Progressive somatic or psychiatric diseases which can affect the course of training

- Referred to rehabilitation primarily due to gynaecological, neurological conditions (apoplexies) or surgeries where movement restrictions are recommended

- Daily medication that may impact muscle protein synthesis (eg, daily antimicrobial drugs acting on ribosome level or prophylactic oral chemotherapy)

- Alcohol intake greater than 14 units per week ( 1 unit=12g/1.5 cl.)

Advice against participation from a general practitioner

\section{Eligibility criteria}

All citizens referred to the rehabilitation centre aged 65 years and older will be invited to a screening interview with a physiotherapist; any of the criteria listed in box 1 causes ineligibility.

\section{INTERVENTIONS}

\section{Intervention programs}

IPET with protein-enriched yoghurt supplements (IPET+P)

The participants will be prescribed individualised progressive exercise programmes, lasting approximately $40 \mathrm{~min}$ for each individual at each training session. Data collected at baseline are used to design the IPET.

Training will be performed on three non-consecutive days a week for 12 weeks.

The exercise regime constructed based on individual health checks and existing guidelines/recommendations for older individuals. Inspired by the IPET concept the programmes will be composed of three major training categories: aerobic training, functional training and resistance training. ${ }^{16}$

Aerobic training will be conducted using predefined exercises at intensities 13-14 on Borg's rated perceived exertion-scale, corresponding to $60 \%-80 \%$ of the HR. ${ }^{23}$ The participants will be able to choose among six aerobic exercises that suit their condition with guidance from the physical therapist: cycling, walking, stepping, walking lunges, jumping jacks, ski jumps. The aerobic exercise will be conducted in blocks of $10 \mathrm{~min}$. Progression and regression for each exercise is monitored by the physiotherapist and will mainly be managed by: adjusting the tempo/ cadence, reducing the demands for balance by increasing the supporting surface using walking aids/walls, change of position from standing to sitting and finally reducing the range of movement in the exercise.

Functional training will be based on six exercises inspired primarily from the Otago exercise protocol and
Thai Chi movements, which has been shown to affect balance outcomes. ${ }^{24}{ }^{25}$ The functional exercises will be conducted in blocks of $5 \mathrm{~min}$. For example, if allocated to ten minutes of functional training one would be given two exercises to practice. Progression and regression for each exercise will be done based on the same principles as mentioned earlier under the aerobic exercises, so the exercise fits the level of the participant.

Resistance training exercises will be conducted using Thera-Band elastic bands with a magnetically attached sensor. Six exercises for each body part (Elbow/hands, shoulder/upper back, neck, lower back, hip and knee/ankle), has been predefined and prioritised. Six compound exercises for upper extremity, lower extremity and total body exercises have also been predefined. The resistance training will be conducted in blocks of $5 \mathrm{~min}$, using periodisation with intensities $2-4$ sets and 8-15 RM with a 60 s rest between sets.

The sport sensor attached to the Thera-Band elastic bands measures the number of repetitions, sets and time under tension, which are known components that affect muscular adaptation to resistance exercise. ${ }^{26}$ Using the in-built sensor in combination with intensive supervision at the beginning of a training period has the potential to contribute to increased compliance throughout the resistance exercises training period among older citizens. However, the feasibility of the technology in clinical practice is yet to be tested.

The algorithm for planning the intervention will be published separately. After careful supervision of the first 2 weeks, a gradual transition to primarily self-administered training is planned, resulting in 18 supervised and 18 selfadministered training sessions. Furthermore, this group will be provided with protein-enriched yoghurts during the intervention period.

UC treatment with protein-enriched yoghurt supplements $(\mathrm{UC}+\mathrm{P})$ In UC, participants receive elements of physiotherapy as deemed appropriate by the physiotherapist for the individual participant. The physiotherapist registers the content of the care given, which is usually composed of some type of physical exercises with or without other treatment modalities (eg, manual therapy or electrical stimulation). Normally, UC is offered for 4 weeks. Exercise volume, intensity and frequency vary across citizens. Further, this intervention group will be provided with protein-enriched yoghurts during the intervention period.

\section{UC treatment}

This group serves as the control group and will be monitored closely as described with $\mathrm{UC}+\mathrm{P}$ but will not be provided with protein-supplements.

\section{Protein-enriched yoghurts}

The protein supplementation will be offered to the participants in the form of high quantity and quality of proteins in low volume yoghurts twice daily $\sim 14 \mathrm{~g}$ of 
protein $(12.5 \mathrm{~g}$ of whey, $1.25 \mathrm{~g}$ of casein) in bottles of $125 \mathrm{~mL}$ (Arla Protino Plus: 788-839kJ, $11 \mathrm{~g}$ protein, $11 \mathrm{~g}$ fat, $11-15 \mathrm{~g}$ carbohydrate per $100 \mathrm{~mL}$ ). Three flavours will be available to avoid taste fatigue (blueberry, raspberry and vanilla/lemon).

The following recommendations for protein intake will be given:

'On training days ingest the first yoghurt immediately after the training/exercise. On non-training days, ingest the first serving of yoghurt in the morning with breakfast. The second serving should be ingested with another meal.' Even though the total daily protein intake is the most important factor for stimulating hypertrophy and strength, there is a skewness towards less protein being ingested during breakfast in the older population. ${ }^{27} 28$

The second serving should be ingested with another meal, since supplementing mixed-nutrient meals with essential amino acids may enhance the muscle protein synthesis in ageing muscles further. ${ }^{29}$ Prior studies have found an effect on functional strength measures and lean body mass using approximately the same quantities of protein of $15 \mathrm{~g}$ as used in the present trial. ${ }^{30} 31$

\section{Compliance to protein intake and physical training}

Participants in the groups IPET $+\mathrm{P}$ and $\mathrm{UC}+\mathrm{P}$ will be asked to store all provided yoghurt bottles, which will be collected and weighed to determine compliance of the protein supplement (consumed protein/delivered protein). The same approach has been used in the study by Gade $e t a l^{32}$ providing more valid results than asking participants to register consumption themselves. Participants in the IPET $+\mathrm{P}$ group performing resistance exercises will receive a sports sensor to attach to the elastic bands to investigate compliance with home-based resistance training. The sports sensor registers time under tension, repetitions, set, frequency and intensity based on how hard and long the elastic band is pulled. ${ }^{1933}$

Additionally, participants will track their own exercise completion for the aerobic- and functional component, and report at the weekly follow-ups if they skipped some of the exercises.

\section{Outcomes}

A blinded assessor will collect all outcome measures (see table 1) on the same time and day of the week preintervention and postintervention. The entire test session is

Table 1 Summary of outcome measures to be collected

\begin{tabular}{ll} 
Outcome measures & Data collection instrument (unit) \\
\hline Primary outcome & Questionnaire \\
Short Musculoskeletal Function Assessment-Dysfunction Index &
\end{tabular}

\section{Secondary outcomes}

ICF-body functions and structures

\begin{tabular}{|c|c|}
\hline $\begin{array}{l}\text { Anthropometrics (height, weight, lean body mass, fat percentage, total } \\
\text { body water, visceral fat, body mass index) }{ }^{41} 42\end{array}$ & $\begin{array}{l}\text { Measuring tape (Exacta, North Coast Medical, California, USA) } \\
\text { Tanita 9MC-780U Multi Frequency Segmental Body Composition } \\
\text { Analyzer (Tokyo, Japan) }\end{array}$ \\
\hline Basic metabolic rate r1 $^{41}$ & $\begin{array}{l}\text { Tanita 9MC-780U Multi Frequency Segmental Body Composition } \\
\text { Analyzer (Tokyo, Japan) }\end{array}$ \\
\hline Blood pressure and resting heart rate 42 & OMRON HBP 1100 (Kyoto, Japan) \\
\hline Waist-to-hip ratio 4243 & Measuring tape (Exacta, North Coast Medical, California, USA) \\
\hline Maximal voluntary isometric contraction (knee extension) $)^{43}$ & Strain gauge/TheR2Force \\
\hline Handgrip strength ${ }^{43} 44$ & Hydraulic hand dynamometer (SAEHAN, Masan, South Korea) \\
\hline \multicolumn{2}{|l|}{ ICF-activity level } \\
\hline Timed up and $\mathrm{go}^{60}$ & Chair (46 cm in height), stopwatch and measuring tape \\
\hline 2 min walk test ${ }^{47}$ & $\begin{array}{l}\text { Stopwatch, measuring tape, Borg's RPE-scale, HR monitor (Apple } \\
\text { Watch, Series V.5, } 44 \mathrm{~mm} \text {, California, USA) }\end{array}$ \\
\hline 5RM (leg press, knee extension, calf extension) ${ }^{43}$ & Technogym training equipment (Cesena, Italy) \\
\hline Balance and reaction time ${ }^{5061}$ & Fysiometer (Fysiometer ApS, Broenderslev, Denmark) \\
\hline Tandem balance test ${ }^{51}$ & Stopwatch \\
\hline \multicolumn{2}{|l|}{ ICF-participation level } \\
\hline $\mathrm{NMS}^{52}$ & Questionnaire \\
\hline PRISMA- $7^{53}$ & Questionnaire \\
\hline $\mathrm{TFI}^{54}$ & Questionnaire \\
\hline SF-36 $6^{55}$ & Questionnaire \\
\hline Self-formulated questions regarding site and intensity of pain & Questionnaire \\
\hline
\end{tabular}

ICF, International Classification of Functioning; NMS, New Mobility Scale; PRISMA, Program of Research on Integration of Services for the Maintenance of Autonomy; RM, repetition maximum; SF36, Short Form 36; TFI, tilburg frailty indicator. 
expected to last 90-120 min for each individual at baseline and at 3 and 12 months follow-up.

Furthermore, 24 hours historical food interviews will be conducted, as described by Gade $e t a l,{ }^{34}$ at baseline, week 3 , week 6 , week 9,3 months and 12 months for all participants to determine total energy intake.

\section{Sample size}

The sample size calculations were performed using Stata (V.13.1). To detect a significant treatment effect of 10 points on the SMFA-D operationalised by pairwise differences between groups (UC vs $\mathrm{UC}+\mathrm{P}, \mathrm{UC}$ vs IPET $+\mathrm{P}$ and $\mathrm{UC}+\mathrm{P} v$ s $\mathrm{IPET}+\mathrm{P})$, assuming an overall significance level of 0.05 , power of 0.80 and an effect size of 0.67 (expected mean difference of 10 points divided by the SD of 15 points), a total of 147 participants are required. ${ }^{35-39} \mathrm{~A}$ drop-out rate of $20 \%$ from baseline to post-assessment is assumed, resulting in a target of about 177 participants for initial inclusion in the trial.

\section{Methods: assignment of interventions \\ Randomisation and blinding}

The trial will use block randomisation, stratified by age and gender, to form the allocation list for the three comparison groups. An independent researcher will generate random permuted blocks with random block sizes of 6,9 and 12 participants and a 1:1 allocation ratio using the simulation tool at www.sealedenvelope.com. Sequentially sealed opaque envelopes will then be distributed to the participants after the testing session.

Staff included in the screening process, as well as the principal investigator, outcome assessor and participants, will all initially be blinded to the allocation. The outcome assessor will remain blinded to allocation during the entire trial.

\section{Methods: data collection, management, and analysis Data collection}

In order to assure high reliability and validity of testingthe entire testing procedure is planned to be conducted on citizens matching eligibility criteria before starting the trial.

Furthermore, after every 10 weeks, a brush-up course will be conducted by the principal investigator to align testing procedures continuously during the entire trial period. All postinterventional tests will for each participant be conducted on the same day and time of the week as at baseline.

\section{Primary outcome}

SMFA is a 46-item questionnaire composed of two subscales, a 34-item dysfunction index and a 12-item bother index that assesses the impact of a wide variety of disorders on everyday life. ${ }^{40}$ The questionnaire evaluates self-reported function, and how bothered the older citizens are by their symptoms. A previous study has shown that the SMFA can be a valid and responsive measure of outcomes of rehabilitation in a Danish rehabilitation setting. ${ }^{35}$

\section{Secondary outcomes}

Body composition: Segmental body fat, fat-free mass, total body water, visceral fat index, and basic metabolic rate will be analysed using a bioimpedance (Tanita 9MC780U Multi Frequency Segmental Body, Tokyo, Japan).$^{41}$

Blood pressure will be measured using an electronic sphygmomanometer (OMRON HBP 1100, Kyoto, Japan). Three measures will be taken on the left arm after the subject has been lying in a supine position for 5 min. ${ }^{42}$

Waist and hip circumference: Waist circumference will be measured using a stretch-resistant measuring tape (Exacta, North Coast Medical, California, USA) at the narrowest part of the torso, and hip circumference at the maximal circumference of the hip just below the gluteal fold. $^{42}$

Maximal voluntary isometric contraction (MVIC) will be measured for knee extension in the left leg. Participants will be seated in sitting position with the knees and hips in a $90^{\circ}$ angle, with a strain gauge applied over the malleolus. ${ }^{43}$

Handgrip strength for both hands will be assessed standing against a wall with a $90^{\circ}$ elbow flexion using a hydraulic hand dynamometer (SAEHAN, Masan, South Korea) using handle position two (consequently all participants will perform the measurement with the handle at a specific distance) ${ }^{44}$ Verbal encouragement will be given for both testing of handgrip strength and MVIC for knee extension, and the highest produced force will be taken as the maximal voluntary contraction.

Muscle strength will be tested as 5 RM in the leg press, calf extension, and knee extension following the protocol from Burich et al. ${ }^{43}$

The Timed up and go' test is measured as time to rise from a chair, walk $3 \mathrm{~m}$, turn and go back and return to sitting. ${ }^{45} 46$

In the 2 min' walk test, participants will be asked to walk as many times as possible on a $30 \mathrm{~m}$ lane. ${ }^{47}$ Perceived exertion and heart rate will be recorded just before and after the test. Heart rate will be recorded manually with a wrist-worn device (left hand) that has integrated photoplethysmography (Apple Watch, Series V.5, 44mm, California, USA). ${ }^{23} 4849$

A Wii Balance Board (Nintendo, Kyoto, Japan), in combination with the Fysiometer software (Fysiometer ApS, Broenderslev, Denmark), will be used to collect data on static balance and reaction time for upper and lower extremities. ${ }^{50}$

Tandem test scores for progressively difficult postures will also be collected. ${ }^{51}$

A range of patient-reported outcomes will be collected to reflect different aspects of the ICF parameters: The New Mobility Score can be used to estimate the degree of limitation in basic mobility. ${ }^{52}$ Program of Research on Integration of Services for the Maintenance of Autonomy (PRISMA-7) questionnaire has been proven to have the potential to determine the degree of frailty, especially when combined with tests evaluating basic mobility. ${ }^{53}$ In order to investigate the degree of frailty with a multidimensional approach, scores from the Tilburg Frailty Indicator will also be collected. ${ }^{54}$ The Short Form-36 questionnaire assesses health-related quality of life. ${ }^{55} \mathrm{Few}$ 
self-formulated questions regarding site and intensity of pain will also be asked.

All questionnaires will be filled out by the participants in their own homes. Participants will bring the completed questionnaire to the baseline assessment, where any questions may be answered, and questionnaires checked for missing answers, and the participant will be asked to give a final answer.

\section{Statistical analysis/methods}

All statistical analyses will be performed using Stata IC V.16 (script files will be stored). Data will first be treated with an intention-to-treat approach and second with per-protocol sensitivity analysis, only including participants from IPET $+\mathrm{P}$ with attendance to physical exercise $\geq 70 \%$ and with compliance to the protein-enriched yoghurts $\geq 70 \%$.

As we expect to include participants having various health-related disorders, subgroup analysis will also be performed to investigate the impact of for example, disorder, activity level, and frailty status on outcome measures. Fitted residuals will be visually inspected for normality. The significance level is set at alfa $<0.05$ (two tailed), and data will be presented as medians with interquartile ranges or means with SD or CIs.

To analyse the between-group difference of the primary outcome (SMFA-D), mixed-effects linear regression models will be used. Random effects (time and intervention) will be conducted to account for variability among included participants, and relevant covariables will be tested in fixed-effect tests, for example, age and gender. Secondary outcomes will be tested for corresponding differences as an underlying mechanism for changes in function. All secondary outcome variables (table 1) will be analysed in the same manner as the primary outcome.

\section{Patient and public involvement}

Patients and/or the public were not involved in the design, or conduct, or reporting, or dissemination plans of our research.

\section{ETHICS AND DISSEMINATION}

This trial will be conducted in accordance with the Belmont Report and the declaration of Helsinki. Written and oral information regarding the trial will be given to the participants, and a signed informed consent will be obtained prior to the inclusion of every participant.

Results will be published in scientific journals and presented at international conferences.

There are no known side effects of increasing the amount of protein in the quantities used in this present trial. Protein-enriched yoghurts from Arla are sold generally in stores in Denmark. It is a legal requirement that rehabilitation for citizens ( $\$ 140$, Danish health act) is initiated within 7 days of referral. This is a challenge for the municipalities as the number of citizens referred for rehabilitation greatly exceeds the number of available therapists. Due to this fact, the research team predicts that it can be challenging to find available time for some participants allocated to UC within 7 days, which can result in a later start after baseline testing compared with participants assigned to IPET $+\mathrm{P}$.

In the case of readmission to hospitals, participants will still be offered a follow-up test, and advised to continue their rehabilitation if there are no contradictions.

\section{DISCUSSION}

This trial investigates the effect of different rehabilitation strategies on all three ICF parameters, by comparing IPET $+\mathrm{P}$ supplement against $\mathrm{UC}$ and $\mathrm{UC}$ in combination with protein supplement. Further, the trial investigates whether UC in combination with enhanced protein intake will potentiate more significant improvements in outcome measures than UC alone.

\section{Setting and applicability}

This trial will have high external validity and generalisability, because it has a pragmatic approach and is conducted in a clinical setting at two municipality rehabilitation centres and performed by clinical health professionals in collaboration with the target group. Consequently the gap between research and clinical practice is diminished, and the effect of the interventions will become apparent. ${ }^{56}$ The trial may inform on how the expenses of health-related services and secondary problems for individuals undergoing rehabilitation may be reduced. Specific and straightforward guidance to therapists in rehabilitation centres regarding protein intake and exercise prescription for the older population can be issued and implemented if the intervention is proven effective.

\section{Target group}

In 2018, we presented descriptive data of 53 hospitalised geriatric patients at the World Congress on Osteoporosis, Osteoarthritis, and Musculoskeletal Diseases. ${ }^{57}$ The data showed that participants had a median of 7 diagnoses (IQR 6-10), indicating a large number of comorbidities. Hospitalised olders usually start rehabilitation in a municipality rehabilitation centre after 7 days of discharge, accentuating a likely similarity to those enrolled in this trial. We anticipate that participants in this trial will be referred to rehabilitation with a broad range of disorders, this taken into consideration with the fact that rehospitalisation after discharge is common among older citizens, one might question the compliance of the intervention. ${ }^{58}$

\section{Evaluation of effect and impact at an individual level}

The comprehensive testing may disclose the impact of interventions on all three ICF parameters is unique to this trial. It is reasonable to assume that effects on activity and participant level of the ICF, in particular, will have an impact on clinicians and their willingness to implement new interventions in practice if proven effective. Because physical, mental and social 
characteristics will be assessed the participants, different components and their impact on outcomes can be investigated further. This knowledge can be used to individualise efforts towards older citizens, thus improving the chances of offering the correct rehabilitation to each individual accordingly. By carefully monitoring the participants in the UC group, a unique opportunity is also available to observe and describe the current practice.

\section{Limitations}

Due to the heterogeneity expected among participants with many comorbidities, a limitation might be that some participants will not be able to complete the entire testing session at once. Since research has not stated an optimal testing organisation, the researchers in this trial have discussed this and decided to align with guidelines from American College of Sports Medicine. Introduction of the next test in line will first be conducted when the heart rate is returned to almost baseline values together with each participant's perception of whether they are ready for the next test. ${ }^{42}$

With regard to nutrition intake, the tool is a 24-hour recall interview, which has its limitations in accuracy and food-item variability. Hence, measurements on especially micronutrient intakes may be unreliable, whereas energy intake may be better evaluated.

It is a limitation to focus on enhancing one macronutrient in a target group at risk of undernutrition since there is a risk of mal consumption-especially inadequacy of other macros- and micronutrients. General energy-inadequacy is a risk factor and may counteract any anabolic benefits of interventions. ${ }^{10}$ Vitamin D is a micronutrient closely linked to muscle function. ${ }^{59} \mathrm{~A}$ known limitation of this trial is the lack of control of the participants' initial vitamin D status, resulting in a risk of insufficient levels of vitamin $\mathrm{D}$, which can cause impaired muscle and physical functioning. ${ }^{59}$ In Denmark, specifically, vitamin $\mathrm{D}$ and iron consumption may not be sufficient despite the intake of a diet on healthy foods. The protein-enriched yoghurts have vitamin $\mathrm{D}$ added to them; however, it is only $1.2 \mu \mathrm{g} / 100 \mathrm{~mL}$, which we do not expect to have a significant impact on the participants' overall vitamin D status.

The lack of a clear systematic approach to patient and public involvement in this study might be considered as a limitation.

\section{TRIAL STATUS}

The trial is currently active, with several participants commenced the study.

Acknowledgements We thank all the funding parties for financially supporting this trial. We thank Arla Foods amba for providing samples of Protino Pro Plus. Further, a special thanks to Slagelse Municipality, Sundhed \& Træning for enabling the trial setting.

Contributors All authors have been involved in forming the detailed project description. ST and LH prepared the grant applications. ST, KS, TD, LFS, NON and LH elaborated on the trial protocol. GS and TD contributed to the design of individualised physical exercise training. ST wrote the first draft and is the guarantor of the manuscript; all authors contributed and have approved the final version. None of the sponsors were involved in the trial design and will not be a part of the collection, management, analysis, and interpretation of data.

Funding This trial (case number 8045-00052B) has been reviewed by The Danish Council for Independent Research (IRFD) and Research Committee for Physiotherapists (RCP). The project has been granted 2.589.134 DKK (incl. $44 \%$ overhead) from IRFD, 290.000 DKK from RCP, and 373.026 DKK from University College Absalon. The total budget for this project is 3.252.160 DKK. Furthermore, Arla AMBA will sponsor 21.240 bottles of protein-enriched yoghurts for the entire trial, the retail price of which is approximately 212.000 DKK.

Competing interests None declared.

Patient and public involvement Patients and/or the public were not involved in the design, or conduct, or reporting, or dissemination plans of this research.

Patient consent for publication Not required.

Provenance and peer review Not commissioned; externally peer reviewed.

Open access This is an open access article distributed in accordance with the Creative Commons Attribution Non Commercial (CC BY-NC 4.0) license, which permits others to distribute, remix, adapt, build upon this work non-commercially, and license their derivative works on different terms, provided the original work is properly cited, appropriate credit is given, any changes made indicated, and the use is non-commercial. See: http://creativecommons.org/licenses/by-nc/4.0/.

ORCID iDs

Sanel Teljigovic http://orcid.org/0000-0001-7784-7451

Karen Søgaard http://orcid.org/0000-0003-3968-6364

Louise Fleng Sandal http://orcid.org/0000-0001-8436-1046

\section{REFERENCES}

1 Eatock D. Demographic outlook for the European Union 2019 [Internet]. EPRS - European Parliamentary Research Service. 2019. Available: https://www.europarl.europa.eu/RegData/etudes/IDAN/ 2019/637955/EPRS_IDA(2019)637955_EN.pdf

2 Eurostat. People in the EU: who are we and how do we live? [Internet]. p. 174, 2015. Available: https://ec.europa.eu/eurostat/ documents/3217494/7089681/KS-04-15-567-EN-N.pdf

3 Regioner D. Flere ældre betyder flere patienter $i$ sundhedsvæsenet, 2019: 1-2. https://www.regioner.dk/media/11765/faktaark_flereaelreuhi2.pdf

4 Dharamshi R. The future of care for frail elderly patients: our first steps towards progress. Postgrad Med J 2014;90:427-8.

5 World Health Organization. Towards a common language for functioning, disability and health: ICF. Int Classif 2002;1149:1-22 http://www.who.int/classifications/icf/training/icfbeginnersguide.pdf

6 Marengoni A, Angleman S, Melis R, et al. Aging with multimorbidity: a systematic review of the literature. Ageing Res Rev 2011;10:430-9.

7 Walston JD. Sarcopenia in older adults. Curr Opin Rheumatol 2012;24:623-7.

8 Breen L, Phillips SM. Skeletal muscle protein metabolism in the elderly: Interventions to counteract the 'anabolic resistance' of ageing. Nutr Metab 2011;8:68.

9 Dideriksen K, Reitelseder S, Holm L. Influence of amino acids, dietary protein, and physical activity on muscle mass development in humans. Nutrients 2013;5:852-76.

10 The Danish Health Authority. National clinical guideline for nutrition and training interventions aimed at elderly persons with geriatric complications, 2016.

11 Caspersen CJ, Powell KE, Christenson GM, et al. Physical activity, exercise, and physical fitness: definitions and distinctions for healthrelated research. Public Health Rep 1985;100:126-31.

12 WHO. Global recommendations on physical activity for health. Geneva World Heal Organ [Internet]. 2010;60. Available: https://apps. who.int/iris/bitstream/handle/10665/44399/9789241599979_eng. pdf?sequence $=1$

13 Jack K, McLean SM, Moffett JK, et al. Barriers to treatment adherence in physiotherapy outpatient clinics: a systematic review. Man Ther 2010;15:220-8.

14 Kruger J, Brown DR, Galuska DA, et al. Strength training among adults aged >65 years. MMWR Morb Mortal Wkly Rep 2004;53:25-8.

15 Pilgaard M, Rask S. Danskernes motions- og sportsvaner 2016, 2016.

16 Sjøgaard G, Justesen JB, Murray M, et al. A conceptual model for worksite intelligent physical exercise training - IPET - intervention for decreasing life style health risk indicators among employees: a randomized controlled trial. BMC Public Health 2014;14:1-12. 
17 Conn VS, Burks KJ, Pomeroy SH, et al. Older women and exercise: explanatory concepts. Womens Health Issues 2003;13:158-66.

18 Faber M, Andersen MH, Sevel C, et al. The majority are not performing home-exercises correctly two weeks after their initial instruction-an assessor-blinded study. PeerJ 2015;3:e1102.

19 Skovdal Rathleff M, Thorborg K, Bandholm T. Concentric and eccentric time-under-tension during strengthening exercises: validity and reliability of stretch-sensor recordings from an elastic exerciseband. PLoS One 2013;8:e68172-11.

20 Bauer J, Biolo G, Cederholm T, et al. Evidence-based recommendations for optimal dietary protein intake in older people: a position paper from the prot-age Study Group. J Am Med Dir Assoc 2013;14:542-59.

21 Reininga IHF, el Moumni M, Bulstra SK, et al. Cross-Cultural adaptation of the Dutch short musculoskeletal function assessment questionnaire (SMFA-NL): internal consistency, validity, repeatability and responsiveness. Injury 2012;43:726-33.

22 Chan A-W, Tetzlaff JM, Gøtzsche PC, et al. Spirit 2013 explanation and elaboration: guidance for protocols of clinical trials. BMJ 2013;346:e7586:1-42.

23 Norton K, Norton L, Sadgrove D. Position statement on physical activity and exercise intensity terminology. J Sci Med Sport 2010;13:496-502.

24 Cambell AJ, Robertson MC. Otago exercise programme to prevent falls in older adults. Indep Heal Willcare 2003;2003:1-31.

25 Gillespie LD, Robertson MC, Gillespie WJ, et al. Interventions for preventing falls in older people living in the community. Cochrane Database Syst Rev 2012;9:CD007146.

26 Rathleff MS, Thorborg K, Rode LA, et al. Adherence to commonly prescribed, home-based strength training exercises for the lower extremity can be objectively monitored using the bandcizer. $J$ Strength Cond Res 2015;29:627-36.

27 Schoenfeld BJ, Aragon AA, Krieger JW. The effect of protein timing on muscle strength and hypertrophy: a meta-analysis. J Int Soc Sports Nutr 2013;10:1-13.

28 Baum J, Kim I-Y, Wolfe R. Protein consumption and the elderly: what is the optimal level of intake? Nutrients 2016;8:359-9.

29 Paddon-jones D, Rasmussen BB. Dietary protein in sarcopenia prevention. Curr Opin Clin Nutr Metab Care 2010;12:86-90.

30 Tieland M, Dirks ML, van der Zwaluw N, et al. Protein supplementation increases muscle mass gain during prolonged resistance-type exercise training in frail elderly people: a randomized, double-blind, placebo-controlled trial. J Am Med Dir Assoc 2012;13:713-9.

31 Maltais ML, Ladouceur JP, Dionne IJ. The effect of resistance training and different sources of postexercise protein supplementation on muscle mass and physical capacity in sarcopenic elderly men. $J$ Strength Cond Res 2016;30:1680-7.

32 Gade J, Beck AM, Andersen HE, et al. Protein supplementation combined with low-intensity resistance training in geriatric medical patients during and after hospitalisation: a randomised, double-blind, multicentre trial. Br J Nutr 2019;122:1006-20.

33 Rathleff MS, Bandholm T, McGirr KA, et al. New exercise-integrated technology can monitor the dosage and quality of exercise performed against an elastic resistance band by adolescents with patellofemoral pain: an observational study. J Physiother 2016;62:159-63.

34 Gade J, Beck AM, Bitz C, et al. Protein-Enriched, milk-based supplement to counteract sarcopenia in acutely ill geriatric patients offered resistance exercise training during and after hospitalisation: study protocol for a randomised, double-blind, multicentre trial. BMJ Open 2018;8:e019210-10.

35 Lindahl M, Andersen S, Joergensen A, et al. Cross-Cultural adaptation and validation of the Danish version of the short musculoskeletal function assessment questionnaire (SMFA). Qual Life Res 2018;27:267-71.

36 Ponzer S, Skoog A, Bergström G. The short musculoskeletal function assessment questionnaire (SMFA): cross-cultural adaptation, validity, reliability and responsiveness of the Swedish SMFA (SMFA-Swe). Acta Orthop Scand 2003;74:756-63.

37 Lindahl M, Andersen S, Joergensen A, et al. Cross-Cultural adaptation and validation of the Danish version of the short musculoskeletal function assessment questionnaire (SMFA). Qual Life Res 2018;27:267-71.

38 Busse JW, Bhandari M, Guyatt GH, et al. Use of both short musculoskeletal function assessment questionnaire and short Form-
36 among tibial-fracture patients was redundant. J Clin Epidemiol 2009;62:1210-7.

39 Hedbeck CJ, Tidermark J, Ponzer S, Johan C, Jan H, et al. Responsiveness of the short musculoskeletal function assessment (SMFA) in patients with femoral neck fractures. Qual Life Res 2011;20:513-21.

40 Williams N. The short musculoskeletal function assessment (SMFA) questionnaire. Occup Med 2016;66:757.

41 Verney J, Schwartz C, Amiche S, et al. Comparisons of a multifrequency bioelectrical impedance analysis to the dual-energy $X$-ray absorptiometry scan in healthy young adults depending on their physical activity level. J Hum Kinet 2015;47:73-80.

42 Pescatello LS, Arena R, Riebe D. ACSM's Guidelines for Exercise Testing and Prescription. Wolters Kluwer Health, 2014: 482.

43 Burich R, Teljigović S, Boyle E, et al. Aerobic training alone or combined with strength training affects fitness in elderly: randomized trial. Eur J Sport Sci 2015;15:773-83.

44 Roberts HC, Denison HJ, Martin HJ, et al. A review of the measurement of grip strength in clinical and epidemiological studies: towards a standardised approach. Age Ageing 2011;40:423-9.

45 Mak MKY, Pang MYC. Balance confidence and functional mobility are independently associated with falls in people with Parkinson's disease. J Neurol 2009;256:742-9.

46 Okumiya K, Matsubayashi K, Nakamura T, et al. The timed "up \& go" test is a useful predictor of falls in community-dwelling older people. J Am Geriatr Soc 1998;46:928-9.

47 Bohannon RW. Normative reference values for the two-minute walk test derived by meta-analysis. J Phys Ther Sci 2017;29:2224-7.

48 Shigematsu R, Ueno LM, Nakagaichi M, et al. Rate of perceived exertion as a tool to monitor cycling exercise intensity in older adults. J Aging Phys Act 2004;12:3-9.

49 Khushhal A, Nichols S, Evans W, et al. Validity and reliability of the apple Watch for measuring heart rate during exercise. Sports Med Int Open 2017;1:E206-11.

50 Clark RA, Mentiplay BF, Pua Y-H, et al. Reliability and validity of the Wii balance board for assessment of standing balance: a systematic review. Gait Posture 2018;61:40-54

51 Rossiter-Fornoff JE, Wolf SL, Wolfson LI, et al. A crosssectional validation study of the FICSIT common data base static balance measures. J Gerontol A Biol Sci Med Sci 1995:50:291-7.

52 Parker MJ, Palmer CR. A new mobility score for predicting mortality after hip fracture. J Bone Joint Surg Br 1993;75B:797-8.

53 Hoogendijk EO, van der Horst HE, Deeg DJH, et al. The identification of frail older adults in primary care: comparing the accuracy of five simple instruments. Age Ageing 2013;42:262-5.

54 Gobbens RJ, Schols JM, van Assen MA. Exploring the efficiency of the Tilburg frailty indicator: a review. Clin Interv Aging 2017;12:1739-52.

55 McHorney CA, Ware JE, Lu JF, et al. The mos 36-item shortform health survey (SF-36): III. tests of data quality, scaling assumptions, and reliability across diverse patient groups. Med Care 1994;32:40-66.

56 Simon GE, Platt R, Hernandez AF. Evidence from Pragmatic Trials during Routine Care - Slouching toward a Learning Health System. N Engl J Med 2020;382:1488-91.

57 Bülow K, Christiansen T, Jørgensen ADB, et al. Hospitalized Geriatric Patients: A Descriptive Study. In: World Congress on osteoporosis, osteoarthritis and musculoskeletal diseases, 2018: 1-594.

58 Pedersen LH, Gregersen M, Barat I, et al. Early geriatric followup after discharge reduces readmissions - a quasi-randomised controlled trial. Eur Geriatr Med 2016;7:443-8.

59 Rejnmark L. Effects of vitamin D on muscle function and performance: a review of evidence from randomized controlled trials. Ther Adv Chronic Dis 2011;2:25-37.

60 Podsiadlo D, Richardson S. The timed "Up \& Go": a test of basic functional mobility for frail elderly persons. J Am Geriatr Soc 1991;39:142-8.

61 Blomkvist AW, Eika F, Rahbek MT, et al. Reference data on reaction time and aging using the Nintendo Wii balance board: a crosssectional study of 354 subjects from 20 to 99 years of age. PLoS One 2017;12:e0189598:1-13. 